\title{
Focal Symmetrical Poliomyelomalacia in a Calf
}

Focal symmetrical poliomyelomalacia (FSP) is a neurological disorder mainly described in pigs in connection with experimental or spontaneous cases of selenium toxicosis (Harrison et al. 1983, Wendt et al. 1992, Wilson et al. 1983 \& 1989). However, a few cases of FSP have been reported in other domestic animals including sheep, goat, and cattle (Innes \& Plowright 1955, Cordy et al. 1984, Bonniwell \& Barlow 1985, Palmer et al. 1986). Common for reports on FSP in other species than pigs is an unsolved aetiology. In cattle only 1 report on FSP has been published previously describing 2 cases (Palmer et al. 1986). The present report describes a further case of FSP in cattle.

A 4-month- old Red Danish $\times$ American Brown Swiss calf ( + ) suddenly became lame on both fore limbs and unwilling to rise. The calf had a swelling around the coronary band and a temperature of $40^{\circ} \mathrm{C}$. The calf was treated with antibiotics by a veterinary surgeon. The condition got severe during the next $24 \mathrm{~h}$, and the calf became unable to stand on the fore limbs while the function of the rear limbs was normal. As the condition progressively got worse during the next week, the calf was euthanized by intravenous injection of pentobarbitone sodium and submitted for necropsy.

Standard necropsy was performed, and samples for histopathology and microbiology were taken. For histopathological examination, the brain and spinal cord were taken in toto together with pieces of liver, lung, kidney, adrenal gland, musculus supraspinatus, m. semitendinosus, and $\mathrm{m}$. gluteus. The tissues

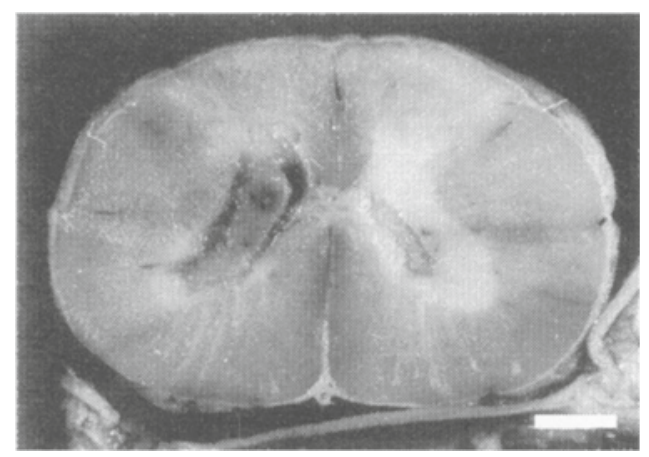

Figure 1. Bilateral poliomyelomalacia in the cervical intumescence. Formalin fixed tissue. Bar = $2.6 \mathrm{~mm}$.

were fixed in $10 \%$ neutral buffered formalin. After fixation, the brain and spinal cord were sliced transversely at 0.5 and $0.3 \mathrm{~cm}$ intervals, respectively, and examined macroscopically. Samples for histological examinations were taken from all levels of the brain and all segments of the spinal cord. The samples were processed routinely and stained with haematoxylin and eosin. The microbiological examinations were performed according to the normal procedures at the National Veterinary Laboratory.

Central nervous system lesions were only found in the spinal cord from $\mathrm{C}_{6}$ to $\mathrm{Th}_{1}$. The total brain weight, the weight of cerebellum, and the ratio between these were within the normal range. The spinal cord lesions were macroscopically characterized by bilateral often almost symmetrical necrosis of the ventral horns with sequestration (Fig. 1). The histopathological evaluation revealed extensive 


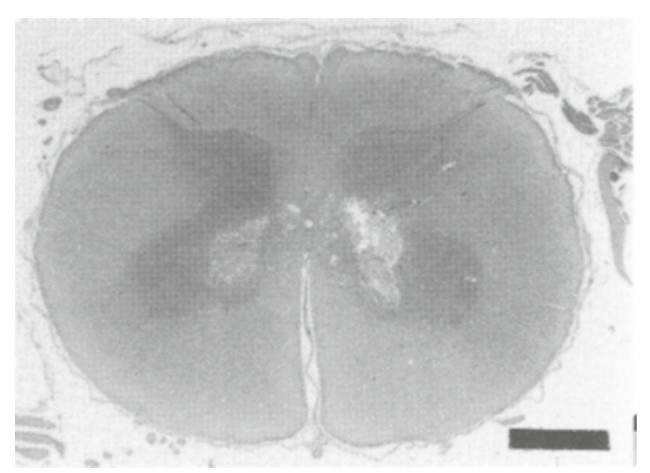

Figure 2. Bilateral almost symmetrical malacia in the ventral horns. Cervical intumescence. Haematoxylin and eosin. Bar $=2.7 \mathrm{~mm}$.

malacia of the spinal cord gray matter from $\mathrm{C}_{6}$ to $\mathrm{Th}_{1}$. In the anterior part of $\mathrm{C}_{6}$ only 1 ventral horn was affected, but malacia occurred in both ventral horns within $0.5 \mathrm{~cm}$ and throughout the remaining affected segments. Extensive malacia was present in the ventral horns leaving only a small rim of gray matter with motor neurons. In addition, in some sections a symmetrical affection of the dorsal horn gray matter was found, while the neuropil and neurons around the central canal were normal (Fig. 2). The pathological changes throughout the affected segments and within each section were similar. The malacia consisted of an extensive infiltration with macrophages replacing the gray matter (Fig. 3). Most neurons had disappeared, but degenerated remnants were found occasionally. Evidence of thrombosis, embolism or vasculitis was not found. In the spinal cord white matter, Wallerian degeneration with swollen axons was present in the ventral and ventro-lateral tracts. Similar changes were found in the ventral radices of the same segments. The evaluation of especially myelin changes was compromised due to autolysis. Pathological changes were not detected neither in the muscles nor in the vis-

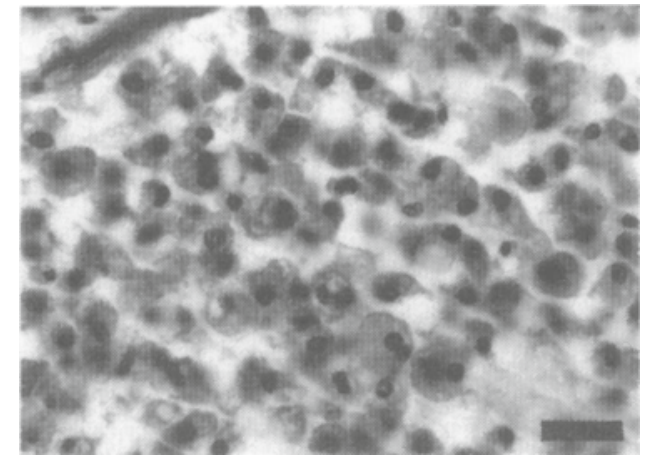

Figure 3. Extensive infiltration with macrophages in the ventral horn. Cervical intumescence. Haematoxylin and eosin. $\mathrm{Bar}=25 \mu \mathrm{m}$.

ceral tissues. Macroscopic changes were not present at the coronary bands.

Microbiological examination revealed a low intestinal infection with coccidia. Bovine virus diarrhoea virus was not detected, but antibodies were present in serum.

The nature and distribution of lesions were those of a focal poliomyelomalacia, and as the changes occurred symmetrically in general, the condition was termed FSP. The histological changes were similar to those previously described in calves (Palmer et al. 1986) with a cellular response dominated by macrophages, but different from FSP in pigs in which eosinophils and microglia dominate (Harrison et al. 1983, Wilson et al. 1983). The location within the spinal cord differs from previous observations in calves. Palmer et al. (1986) found 1 calf with malacia in both the cervical and lumbar intumescences and 1 with malacia in the lumbar intumescence only. However, the distribution of lesions within the spinal cord does not seem critical for the diagnosis, as Innes \& Plowright (1955) in a major outbreak of ovine FSP found 8 cases with only cervical involvement and 3 with both cervical and lumbar involvement. 
Experimental studies have revealed that FSP in various species can be caused by selenium toxicosis, acute nicotinamide deficiency, administration of 6-aminonicotinamine (nicotinamide antagonist), and spinal cord ischemia (DeGirolami \& Zivin 1982, Wilson et al. 1983, 1989). As no selenium assays were undertaken in the present case, the possible role of selenium intoxication is unknown. However, as no other cases or signs of selenium toxicosis appeared in the herd, and as selenium had not been administered to the calf, that aetiology seems unlikely. Furthermore, the inflammatory reaction differed from that described in selenium intoxicated pigs (Harrison et al. 1983). Signs of thrombosis, embolism or vasculitis which could have resulted in ischemia, were not detected. The focal bilateral, almost symmetrical distribution of the lesions and the nature of the cellular response makes an infectious aetiology unlikely, thus leaving the aetiology of the present case unknown.

\section{J. S. Agerholm}

National Veterinary Laboratory

Department of Pathology and Epidemiology

Bülowsvej 27, DK-1790 Copenhagen V, Denmark.

\section{References}

Bonniwell MA, Barlow RM: Ataxia/paresis syndrome of sheep in West Africa associated with bilateral multifocal cerebrospinal poliomalacia.
Vet. Rec. 1985, 116, 94-97.

Cordy DR, East NE, Lowenstine LJ: Caprine encephalomyelomalacia. Vet. Pathol. 1984, 21, 269273.

DeGirolami U, Zivin, JA: Neuropathology of experimental spinal cord ischemia in the rabbit. J. Neuropathol. Exp. Neurol. 1982, 41, 129-149.

Harrison LH, Colvin BM, Stuart BP, Sangster LT, Gorgacz EJ, Gosser HS: Paralysis in swine due to focal symmetrical poliomalacia: possible selenium toxicosis. Vet. Pathol. 1983, 20, 265-273.

Innes JRM, Plowright W: Focal symmetrical poliomalacia of sheep in Kenya. J. Neuropathol. Exp. Neurol. 1955, 14, 185-197.

Palmer AC, Lamont $M H$, Wallace $M E$ : Focal symmetrical poliomalacia of the spinal cord in Ayrshire calves. Vet. Pathol. 1986, 23, 506-509.

Wendt $M$, Jacobs $M$, Mühlum A, Matschullat $G$, Vogel $R$ : Selenintoxikation bei Mastschweinen (Selenium toxicosis in fattening pigs). Tierärztl. Prax. 1992, 20, 49-54.

Wilson TM, Scholtz RW, Drake TR: Selenium toxicity and porcine focal symmetrical poliomyelomalacia: description of a field outbreak and experimental reproduction. Can. J. Comp. Med. $1983,47,412-421$.

Wilson TM, Hammerstedt RH, Palmer IS, deLahunta $A$ : Porcine focal symmetrical poliomyelomalacia: experimental reproduction with oral doses of encapsulated sodium selenite. Can. J. Vet. Res. 1988, 52, 83-88.

Wilson TM, Cramer PG, Owen RL, Knepp CR, Palmer IS, deLahunta A, Rosenberger JL, Hammerstedt $R H$ : Porcine focal symmetrical poliomyelomalacia: test for an interaction between dietary selenium and niacin. Can. J. Vet. Res. $1989,53,454-461$.

(Received August 23, 1993; accepted August 31, 1993).

Reprints may be requested from: J. S. Agerholm, Department of Pathology and Epidemiology, National Veterinary Laboratory, Bülowsvej 27, DK-1790 Copenhagen V, Denmark. 
